\title{
A seven-year review of measured hearing levels in male manual steelworkers with high initial thresholds
}

\author{
R. W. HOWELL* \\ From the British Steel Corporation, Grosvenor Place, London, SW1
}

\begin{abstract}
Audiometric records of 449 male manual steelworkers were reviewed to see whether the hearing of men with high initial threshold levels deteriorated more rapidly than that of those men with more normal thresholds when exposed to similar noise levels. Subjects were between 15 and 54 years old at the time of initial examination, and had a repeat audiogram 6-8 years later. They were classified into three occupational noise exposure groups: below $90 \mathrm{~dB}(\mathrm{~A}), 90-99 \mathrm{~dB}(\mathrm{~A})$, and $100 \mathrm{~dB}(\mathrm{~A})$ or over, without knowledge of their audiometric threshold levels, age, or aural history. Measurements at $0 \cdot 5,1,2,3,4$ and $6 \mathrm{kHz}$ for the right ear were considered, first as the mean for all six frequencies, then for $0 \cdot 5,1$ and $2 \mathrm{kHz}$ only, and finally for $6 \mathrm{kHz}$ only. After standardisation for age, it was found that those in the high initial threshold groups deteriorated no faster than the remainder of the series. At the 90-99 $\mathrm{dB}(\mathrm{A})$ noise exposure level, $\chi^{2}$ tests showed that the differences between the groups, in terms of mean measured hearing loss, were not significant at the 0.05 probability level. The age-standardised mean threshold shifts for the $0.5-6 \mathrm{kHz}$ range of frequencies over the seven-year review period were $7 \cdot 5,8.7$ and $7 \cdot 1 \mathrm{~dB}$ at a noise exposure level of $100 \mathrm{~dB}(\mathrm{~A})$ or more, for workers with an initial threshold level of $<12 \mathrm{~dB}, 12-26 \mathrm{~dB}$ and $>26 \mathrm{~dB}$ respectively; for those exposed to noise of $90-99 \mathrm{~dB}(\mathrm{~A})$ the corresponding mean shifts were $7 \cdot 8$, 6.8 and $7.3 \mathrm{~dB}$ respectively; while for those exposed to noise of less than $90 \mathrm{~dB}(\mathrm{~A})$ the mean shifts were $6 \cdot 2,5 \cdot 0$ and $5 \cdot 2 \mathrm{~dB}$ respectively.
\end{abstract}

There may be a marked and natural reluctance on the part of industrial medical officers to advise men with elevated measured hearing levels to continue to work in noisy environments, partly because there may be little or no margin between current threshold levels and social impairment, and partly because of the fear that those with markedly elevated levels may continue to deteriorate at a faster rate, under similar conditions, than those with more normal levels. I have been unable to discover, from published studies based on reasonable numbers, whether or not those with high initial threshold levels do continue to deteriorate more rapidly. This study was designed to analyse the audiometric records of 449 male manual workers who had a second examination 6-8 years (mean 7 years) after an initial audiogram.

*Epidemiologist. Present address: Courage (Central) Ltd., Bridge Street, Reading, Berkshire.

Received for publication 22 December 1976

Accepted for publication 3 August 1977

\section{Methods}

The noise exposure at work of 533 men who had had a second audiometric examination 6-8 years after an initial examination, was reviewed without reference to age or initial or subsequent hearing threshold levels. Thus any errors in the classification of noise exposure experience would be unbiased by such knowledge and would be randomly distributed among subgroups formed by such factors. Eightyfour men had either changed their place of work and noise exposure in the period under review, and were thus unsuitable for inclusion, or were rejected because of uncertainty about their exposure histories, particularly where jobs involved intermittent noise. The remaining 449 subjects were each classified into one of three noise exposure groups: less than $90 \mathrm{dbB}(\mathrm{A}), 90-99 \mathrm{db}(\mathrm{A})$, or $100 \mathrm{~dB}(\mathrm{~A})$ or over.

All audiograms were made by the same operator, thus obviating one major potential source of error (Howell and Hartley, 1972). Men were between 15 and 54 years of age at the initial audiometric 
examination, and where age is mentioned it is that at the time of first examination. Testing took place in an audiometry booth in a quiet room in a steelworks medical department; the machine (Peters diagnostic audiometer capable of air and bone conduction measurements, with masking facilities) was calibrated to ISO standards. All threshold levels used in this study were based on pure-tone air measurements. An auriscopic examination, with removal of any wax present, was carried out before testing. No subject wore hearing protection, even irregularly, during the period under review, so that this was an unprotected population. The results are based on the differences between the initial and subsequent readings for each subject, for whom three sets of results were calculated, the difference between the mean of readings for the right ear only, at initial and second examination:

(1) at $0.5,1,2,3,4$ and $6 \mathrm{kHz}$ (subsequently referred to as $0.5-6 \mathrm{kHz}$ );

(2) at $0.5,1$ and $2 \mathrm{kHz}$ only;

(3) at $6 \mathrm{kHz}$ only.

The use of the mean of several frequencies is discussed by Burns and Robinson (1970) and is also advocated by Atherley (1973) who points out that there is no wide agreement as to which frequencies should be used. The mean of $0.5-6 \mathrm{kHz}$ has been used to give a comprehensive index, but $0 \cdot 5,1$ and 2 $\mathrm{kHz}$ have also been used, as this combination is frequently taken to cover the area of impaired speech perception (Committee on Medical Rating of Physical Impairment, 1961; Guide for the Conservation of Hearing in Noise, 1964). A reading at $6 \mathrm{kHz}$ alone has also been used because Schneider et al. (1970) found this to be the most sensitive frequency.

For the purpose of looking at changes over the seven-year review period, subjects were classified into three groups to obtain a low, medium and high initial threshold level. For the $0.5-6 \mathrm{kHz}$ results, subjects were classified according to whether they had:

(1) a low initial threshold (mean measured level of less than $12 \mathrm{~dB}$ );

(2) a medium initial threshold (mean measured level between 12 and $26 \mathrm{~dB}$ );

(3) a high initial threshold (mean measured level of more than $26 \mathrm{~dB}$ ).

There may have been several reasons why some men fell into the high initial level group (more than $26 \mathrm{~dB}$ ), including past exposure to higher noise imission levels than other subjects; age (presbycusis); a 'sensitive ear'; and pathological conditions. New pathological lesions arising during the review period would not contribute to any great extent to the mean shift; these lesions would be randomly dis- tributed between the three classification groups because no man was either placed in, or withdrawn from, his working environment on the basis of age, hearing levels or aural history.

For consideration of the $0 \cdot 5,1$ and $2 \mathrm{kHz}$ results, the low, medium and high classifications were based respectively on initial threshold levels of less than $6 \mathrm{~dB}, 6-12 \mathrm{~dB}$, and $13 \mathrm{~dB}$ or more. For the $6 \mathrm{kHz}$ readings the groups were $<20 \mathrm{~dB}, 20-39 \mathrm{~dB}$, and $>39 \mathrm{~dB}$ respectively.

The proportions of men in the low, medium and high initial threshold groups varied in the three groups of frequencies examined. There was no certainty that a man in the low group at $0.5-6 \mathrm{kHz}$ would also be in the low group at $0.5,1$ and $2 \mathrm{kHz}$, but because there is a high correlation between adjacent and nearby frequency measurements, there was a strong tendency for most men to remain in the same low, medium or high group for all three analyses. The fact that the audiometer records in $5 \mathrm{~dB}$ stages and the initial threshold groupings were somewhat arbitrary, also resulted in some, albeit minor, overlap between the groups. Nevertheless, about $25 \%$ of the men examined were in the high initial threshold group throughout the series.

\section{Results}

A simple analysis showed, not surprisingly, that the mean threshold shift varied with noise exposure level, thus providing some validation of the methods used. The mean shifts at $0.5-6 \mathrm{kHz}$ were: $5.6 \mathrm{~dB}$ for the group exposed to $<90 \mathrm{~dB}(\mathrm{~A}) ; 7 \cdot 3 \mathrm{~dB}$ for the group exposed to $90-99 \mathrm{~dB}(\mathrm{~A})$; and $7.8 \mathrm{~dB}$ for the group exposed to $>100 \mathrm{~dB}(\mathrm{~A})$.

Table 1 shows no excess deterioration in the high initial threshold group in these simple results when the proportion of men over 35 years of age is noted.

In industrial surveys the measured threshold levels are unlikely to follow a normal distribution (Howell, 1975). In this series it was noted that the differences obtained from the serial audiograms were also skew and that this skewness tended to increase with the age of the subject. Even logarithmic transformation did not yield a normal distribution, and it would be unwise to rely on parametric tests of significance. Standard deviations have not been calculated.

As age and noise exposure levels clearly affected the simple results in Table 1, calculations were made to allow for these factors, but the large number of subgroupings resulted in small numbers in many cells, with considerable variability. Age-standardisation was therefore carried out to reduce the figures to fewer groups capable of more reliable comparison (Table 2). Standardisation for age, or other factors, 
is a recognised technique (London Transport Executive, 1956; Barker, 1973) and probably its most widely known use is in the preparation of Standardised Mortality Ratios (SMR).

Table 2 shows that the experience of the high initial threshold group compares very favourably with that of the other groups. In none of the nine exposure groups, at various frequencies, does the high initial threshold group undergo the worst (in other words, the greatest) threshold shift. Significance tests would have been useful, but tests based on normal distribution have already been ruled out. Rank order tests were considered, but it was soon noticed that very few of the individual mean values were unique in the series, that is, almost all tied with those of other subjects. Such a preponderance of tied results weakens the value of rank order tests; $\chi^{2}$ tests were then considered.

In the event, only the 90-99 $\mathrm{dB}(\mathrm{A})$ noise exposure group provided sufficient numbers of men to allow for adequate cell sizes when the important age and initial threshold groups were considered. Fortunately this $90-99 \mathrm{~dB}(\mathrm{~A})$ group is the most important, for in

Table 1 Mean seven-year change in threshold levels according to initial threshold level and frequencies tested

\begin{tabular}{lllll}
\hline $\begin{array}{l}\text { Frequencies } \\
\text { tested } \\
(k H z)\end{array}$ & $\begin{array}{l}\text { Initial } \\
\text { threshold } \\
\text { level }(d B)\end{array}$ & $\begin{array}{l}\text { Mean threshold } \\
\text { shift (hearing } \\
\text { loss }) \text { right ear } \\
(d B)\end{array}$ & $N$ & $\begin{array}{l}\text { Men over } \\
35 y r \\
(\%)\end{array}$ \\
\hline $0.5-6$ & $<12$ & $6 \cdot 4$ & 185 & 36 \\
& $12-26$ & $6 \cdot 8$ & 137 & 72 \\
& $>26$ & $7 \cdot 4$ & 127 & 87 \\
$0.5,1,2$ & $<6$ & $4 \cdot 2$ & 213 & 42 \\
& 613 & $5 \cdot 4$ & 114 & 78 \\
& $>20$ & $4 \cdot 3$ & 122 & 80 \\
6 & $20-39$ & $10 \cdot 3$ & 195 & 37 \\
& $>39$ & $12 \cdot 7$ & 122 & 70 \\
& & & 132 & 89 \\
\hline
\end{tabular}

Table 2 Age-standardised mean ${ }^{1}$ threshold shift (right ear) during the seven-year review, according to initial threshold level, noise exposure, and frequencies tested

\begin{tabular}{|c|c|c|c|c|}
\hline $\begin{array}{l}\text { Frequencies } \\
\text { tested } \\
(\mathrm{kHz})\end{array}$ & $\begin{array}{l}\text { Initial } \\
\text { threshold } \\
\text { level }(d B)\end{array}$ & $\begin{array}{l}\text { Mean shift } \\
\text { adB }(A) \text { lev } \\
100+\end{array}$ & $\begin{array}{l}\text { B) after expc } \\
\text { of: } \\
90-99\end{array}$ & $\begin{array}{l}\text { are to noise with } \\
<90\end{array}$ \\
\hline $0 \cdot 5-6$ & $\begin{aligned}< & 12 \\
& 12-26 \\
> & 26\end{aligned}$ & $\begin{array}{l}7 \cdot 5(17) \\
8 \cdot 7(20) \\
7 \cdot 1(19)\end{array}$ & $\begin{array}{l}7 \cdot 8(92) \\
6 \cdot 8(75) \\
7 \cdot 3(81)\end{array}$ & $\begin{array}{l}6 \cdot 2(76) \\
5 \cdot 0(42) \\
5 \cdot 2(27)\end{array}$ \\
\hline $0.5,1,2$ & $\begin{array}{l}<6 \\
\quad 6-13 \\
>13\end{array}$ & $\begin{array}{l}6 \cdot 4(20) \\
5 \cdot 3(19) \\
3 \cdot 9(17)\end{array}$ & $\begin{array}{l}5 \cdot 6(103) \\
5 \cdot 7(64) \\
5 \cdot 3(81)\end{array}$ & $\begin{array}{l}4 \cdot 1(90) \\
3 \cdot 2(31) \\
2 \cdot 8(24)\end{array}$ \\
\hline 6 & $\begin{aligned}< & 20 \\
& 20-39 \\
> & 39\end{aligned}$ & $\begin{array}{l}15 \cdot 1(19) \\
11 \cdot 2(18) \\
10 \cdot 5(19)\end{array}$ & $\begin{array}{c}14 \cdot 5(105) \\
11 \cdot 4(58) \\
9 \cdot 6(85)\end{array}$ & $\begin{array}{r}10.4(71) \\
7.8(46) \\
9.6(28)\end{array}$ \\
\hline
\end{tabular}

No. of men in parentheses.

${ }^{1}$ Standardised means are directly comparable only for the three figures relating tests at a particular frequency after workers' exposure to a specific noise level.
Table 3 Mean threshold shifts tested at 0.5-6 $\mathrm{kHz}$ in men exposed to noise levels of $90-99 \mathrm{~dB}(A)$, according to age and initial threshold level

\begin{tabular}{llrrr}
\hline $\begin{array}{l}\text { Age group } \\
(y r)\end{array}$ & $\begin{array}{l}\text { Initial threshold } \\
\text { level group }\end{array}$ & $\begin{array}{l}\text { No. of men with a mean threshold } \\
\text { shift of: } \\
₹ 7 d B\end{array}$ & $>7 d B$ & Total \\
\hline $15-34^{*}$ & Low & 38 & 25 & 63 \\
& Medium & 15 & 8 & 23 \\
& High & 4 & 5 & 9 \\
& Total & 57 & 38 & 95 \\
$35-44 \dagger$ & Low & 10 & 10 & 20 \\
& Medium & 11 & 11 & 22 \\
& High & 18 & 15 & 33 \\
& Total & 39 & 36 & 75 \\
$45-54_{+}^{+}$ & Low & 4 & 5 & 9 \\
& Medium & 12 & 18 & 30 \\
& High & 21 & 18 & 39 \\
& Total & 37 & 41 & 78 \\
\hline
\end{tabular}

$x^{2}=1 \cdot 0(2$ degrees of freedom) $\mathrm{P}=>10 \%$

$+x^{2}=0.2$ ( 2 degrees of freedom) $P=>10 \%$

$\ddagger x^{2}=1 \cdot 4(2$ degrees of freedom) $\mathrm{P}=>10 \%$.

the group exposed to less than $90 \mathrm{~dB}(\mathrm{~A})$ one would expect little of the threshold shift to be attributable to noise at work. Furthermore, the results in Tables 1 and 2 suggest that the results in all three initial threshold groups are very similar. The $90-99 \mathrm{~dB}(\mathrm{~A})$ group probably represents a far larger body of noise-exposed workers in industry generally than does the group exposed to $100 \mathrm{~dB}(\mathrm{~A})$ or more, though the mean shift per worker will be greater in the latter.

Table 3 shows again that the high initial threshold group has not deteriorated more rapidly than the two other groups, while $\chi^{2}$ tests indicate that the differences in the distributions may well be due to chance $(P>0 \cdot 1)$. It is true that in the $45-54$ year age group the expected number in one cell does not reach 5 , but the test is robust enough for this not to be a serious disadvantage. Furthermore, only the low initial threshold group is thus involved, while the high initial group compares well and favourably with the medium threshold group. Similar $\chi^{2}$ tests for the same noise exposure group (90-99 $\mathrm{dB}(\mathrm{A})$ ) but for $6 \mathrm{kHz}$ only and $0 \cdot 5,1$ and $2 \mathrm{kHz}$ also showed no statistically significant differences for the three initial threshold groups.

Product moment correlation coefficients were also calculated to see if there was a significant relationship between individual initial threshold level and threshold shift over the review period. In none of the 12 groups (four 10-year age groups by three noise exposure groups) was there a statistically significant correlation.

\section{Discussion}

The use of either left or right ear alone is common- 
place in audiometric studies. Examination of 6303 audiograms in the steel industry showed very similar means (within one-fiftieth of a decibel) at each frequency in both left and right ears, although clearly there were differences in some individuals from such causes as unilateral pathology or rifle shooting. The right ear alone has been frequently used (e.g. Jirák et al., 1971; Pell, 1972; Howell, 1975) as has the left (Stephens, 1971). Other authors have used an equal number of right and left ears in different individuals (Rintelman et al., 1972); the better ear (Smith, 1969; Burns and Robinson, 1973; Howell, 1975); both ears combined (Howell and Hartley, 1972; Hartley et al., 1973); while many papers fail to state clearly the ear or ears involved. Baughn (1967) has said, 'Most single ear studies have been reported on the basis of male right ears'. For this study, too, the right ear was chosen.

Noise exposure groupings of below $90 \mathrm{~dB}(\mathrm{~A})$, of $90-99 \mathrm{~dB}(\mathrm{~A})$, and of $100 \mathrm{~dB}(\mathrm{~A})$ or above, were selected. While these ranges are somewhat arbitrary, $90 \mathrm{~dB}(\mathrm{~A})$ is frequently used as a dividing line between noisy and non-noisy environments (Department of Employment, 1972), although there is now increasing opinion in favour of reducing this threshold to $85 \mathrm{~dB}(\mathrm{~A})$ to give a margin of safety. The $100 \mathrm{~dB}(\mathrm{~A})$ threshold certainly denotes a very noisy environment (Cohen et al., 1970). Atherley (1973) has also used $100 \mathrm{~dB}(\mathrm{~A})$ as the starting point in a study of gravure printers. The range 90-99 $\mathrm{dB}(\mathrm{A})$ covers a fairly extensive spread which might be expected to produce noise-induced hearing loss over a period.

This study showed that those with high initial threshold hearing levels deteriorated no faster, under similar noise exposure conditions, than those with lower initial levels, although this finding does not imply that a $10 \mathrm{~dB}$ shif $t$ has similar implications for men with a measured threshold level of $20 \mathrm{~dB}$ as for men with a $40 \mathrm{~dB}$ threshold level. However, any consideration of social impairment or disability suggests medical evaluation and is thus outside the scope of this paper. One reason for this favourable trend, in which the group with initially high thresholds fared better than the group with average thresholds could be the well-known and frequent phenomenon of reversion towards the mean, which has already been suggested by Howell and Hartley (1972) in the context of industrial audiometry. The so-called sensitive ear was obviously seldom if ever present in this study or the results would have been very different. It may be that the sensitive or susceptible ear is damaged at a fairly early stage so that it is no longer particularly sensitive and the rate of deterioration settles to one equivalent to, or even less than, that of more normal ears. Ambient noise levels generally, including noisy hobbies and not merely noise at work, may have stabilised susceptible ears by the time of entry to this study. Certainly the evidence shows that in this study those workers with high initial measured threshold levels did not show a more rapid rate of auditory deterioration than did their colleagues with more normal initial levels.

I am grateful to Dr A. Sinclair (Group Senior Medical Officer) and Dr F. A. Shackleton (Senior Medical Officer), British Steel Corporation (Scunthorpe area) for access to their records; without their co-operation this study would not have been possible.

\section{References}

Atherley, G. R. C. (1973). Noise induced hearing loss. Annals of Occupational Hygiene, 16, 183-192.

Barker, D. J. P. (1973). Practical Epidemiology. Churchill Livingstone: Edinburgh and London.

Baughn, W. L. (1967). Noise control: percent of population protected. International Audiology Journal, 5, 331-338.

Burns, W., and Robinson, D. W. (1970). Hearing and Noise in Industry. HMSO: London.

Burns, W., and Robinson, D. W. (1973). Audiometry in industry. Journal of the Society of Occupational Medicine, 23, 86-91.

Cohen, A., Anticaglia, J., and Jones, H. H. (1970). 'Sociocusis' -hearing loss from non-occupational noise exposure. Sound and Vibration, 4, 12-20.

Committee on Medical Rating of Physical Impairment (1961). Guides to the evaluation of permanent impairment : ear, nose, throat and related structures. Journal of the American Medical Association, 177, 489.

Department of Employment (1972). Code of Practice for Reducing the Exposure of Employed Persons to Noise. HMSO: London.

Guide for the Conservation of Hearing in Noise (1964). Supplement to the Transactions of the American Academy of Ophthalmology and Otolaryngology, p. 12.

Hartley, B. P. R., Howell, R. W., Sinclair, A., and Slattery, D. H. D. (1973). Subject variability in short-term audiometric recording. British Journal of Industrial Medicine, 30, 271-275.

Howell, R. W. (1975). Ear pathology; its role in hearing impairment. Journal of the Society of Occupational Medicine, 25, 28-32.

Howell, R. W., and Hartley, B. P. R. (1972). Variability in audiometric recording. British Journal of Industrial Medicine, 29, 432-435.

Jirák, Z., Mautner, B., Koštál, J., Andél, A., and Losert, C. (1971). Lärmhörschäden bei Bergleuten des OstrauKarwiner Kohlenreviers. Internationales Archiv für Arbeitsmedizin, 28, 49-61.

London Transport Executive (1956). Health in Industry. Butterworth: London.

Pell, S. (1972). An evaluation of a hearing conservation program. American Industrial Hygiene Association Journal, 33, 61-70.

Rintelman, W. F., Lindberg, R. F., and Smitley, E. K. (1972). Temporary threshold shift and recovery patterns from two types of rock and roll music presentation. Journal of the Acoustical Society of America, 51, 1249-1255.

Schneider, F. J., Mutcheler, J. E., Hoyles, H. R., Ode, E. H. 
and Holden, B. B. (1970). The progression of hearing loss from industrial noise exposure. American Industrial Hygiene Association Journal, 31, 368-376.

Smith, P. E. (1969). A test for susceptibility to noise induced hearing loss. American Industrial Hygiene Association
Journal, 30, 245-250.

Stephens, S. D. G. (1971). Some individual factors influencing audiometric performance. In Occupational Hearing Loss, pp. 109-120. Academic Press: London. 